\title{
ACADEMIC ADVISING: PERCEPTIONS OF STUDENTS IN A LEBANESE UNIVERSITY \\ Najwa Saba 'Ayon*
}

*Asst. Prof. Dr., Languages and Humanities Department, Rafik Hariri University, Lebanon, faresns@rhu.edu.lb

\begin{abstract}
A lot of researchers have stressed the impact of academic advising on students' retention, academic success, and satisfaction (Soria, 2012; Young-Jones, Burt, Dixon \& Hawthorne, 2013; Hsu \& Bailey, 2011; Nasser, Khoury, Abouchedid, 2008 among others). However, several students at a Lebanese private university do not seem to value academic advising as they do not usually seek it. Therefore, this study investigates students' perceptions of their academic advising. More specifically, the researcher examines (1) students' awareness of the process of academic advising, as well as the role of an academic advisor, (2) their attitudes towards the academic advising they receive at the university, and (3) the impact of gender, major, and academic status on their attitudes. Using a mixed-methods approach, the researcher surveys a purposively selected sample of 185 students of different majors, gender, and academic statuses and complements the survey with 3 focus groups. Triangulation of methods is used to ensure validity of the findings. Major findings reveal that a lot of the participants seem to perceive academic advising negatively as they had unsatisfactory experiences with their academic advising and advisors. Gender, major, and status did not impact on the participants' attitudes. They seem to be aware of the important role the advising process and the academic advisor could have on their university life. However, their expectations of academic advising did not match with what they received from their advisors. The researcher suggests several changes that are likely to ensure effective academic advising at the university.
\end{abstract}

Keywords: Academic advising, Higher education, Students' perceptions, Students' attitudes, satisfaction, Student awareness, University students, Lebanon

\section{INTRODUCTION}

Recently academic advising has been the subject of investigation by a lot of researchers due to its impact on students' retention, success, and satisfaction (Soria, 2012; Young-Jones, Burt, Dixon \& Hawthorne, 2013; Hsu \& Bailey, 2011; Nasser, Khoury, Abouchedid, 2008 among others). In fact, Young-Jones et al. (2013:9) argue that "academic advising is a point at which student behavior and institutionally controlled conditions meet to potentially influence student achievement".

Being aware of the importance of academic advising, the university, a mid-sized Lebanese private 
university, mandates this process on each student. Specifically, the advising policy stipulates that each student do the following: (1) "sign up to meet [with her/his] advisor", (2) agree with her/his academic advisor on a "complete study plan for her/his bachelor program", (3) "adhere to the study plan agreed upon with the advisor", (4) "consult with her/his advisor to finalize the selection of her/his courses" for each semester, and (5) "secure the signature of her/his advisor on her/his registration form"; otherwise, her/his registered courses "will be automatically deleted" (university website). This policy even warns students against the penalty of not attending the advising sessions, namely students' inability to register their courses online.

Despite this policy on academic advising, a lot of students do not undergo such a requirement before registration. Only a few students visit their advisors just to have them sign their registration form after the students register their courses online. This aroused the researcher's curiosity to investigate students' poor adherence to the policy. Because students' perceptions of academic advising at our university are likely to impact on their behavior, the researcher, thus, aimed to examine their perceptions of their academic advising. More specifically, the researcher examined (1) students' awareness of academic advising as well as the role of an academic advisor, (2) their attitudes towards the academic advising they receive at the university and (3) the impact of gender, major, and academic status on their attitudes .

\section{LITERATURE REVIEW}

This section consists of two sub-sections, the first of which reviews research studies on students' perceptions as well as attitudes toward academic advising in different contexts and majors. The second subsection depicts studies that discuss the impact of advising on students' satisfaction, success, and retention.

\subsection{Students' Perceptions of Academic Advising}

Because academic advising is crucial to students' university experience and involvement on campus (YoungJones, Burt, Dixon \& Hawthorne, 2013; Davis \& Cooper, 2001; Astin, 1984), several researchers have investigated students' perceptions of it. For example, Gudep (2007) surveyed the attitudes of 482 Emirati undergraduates of different majors (Business, Tourism, \& Information systems) toward academic advising. Using factor analysis, the researcher found that the participants had positive attitudes toward advising as indicated by high loadings (between 0.887 and 0.523 ) on 7 factors "Student Oriented Advisors, System Oriented Advisors, Technology Oriented Advisors, Extracurricular Activities Oriented Advisors, Innovation Oriented Advisors, and Non Serious Oriented Advisors" (170). More specifically, the participants revealed that their advisor "displayed a positive attitude toward their problems ...was enjoying his academic advising duties ... [and] displayed a concern for advisees whose GPA was less" (163). They also indicated that their advisors were knowledgeable of and committed to the duties of an advisor as indicated in the catalogue. In addition, to maintain students' satisfaction, the advisors assessed the effectiveness of advising through surveys and open-ended questions given to their advisees. The advisees stated that their advisors, who were aware of the impact of extracurricular activities on students' involvement, encouraged them to take part in such activities. However, the participants noted that some advisors "demonstrated his casual and nonserious attitude" by avoiding meeting with their advisees (164). In this study, Gudep did not find "any significant difference" among the participants' attitudes from different majors and genders (171).

In another quantitative study, Christian and Sprinkle (2013) investigated (1) the perceptions of 125 graduate and undergraduate students (mostly females $76.2 \%$ ) in one department at a mid-sized public university in the US of academic advising, (2) their ideals of the advising style, and (3) the relationship between the two variables. The findings supported most of the researchers' hypotheses: (1) the participants were receiving collaborative or developmental advising ${ }^{1}$, (2) older students preferred collaborative advising, and younger participants preferred prescriptive advising, (3) although ethnicity did not impact on the participants' responses on both variables, gender-unlike Gudep (2007)- did impact on their attitudes, with males' preference for more prescriptive advising ${ }^{2}$, (4) participants with higher GPA, who perceive grades as great motivators, preferred more prescriptive advising, and (5) there is a positive correlation between the participants' perceptions and their ideals of advising. Despite the limitations of the study (not a representative sample), this study shows that "students whose perceptions positively correlate with their ideals of advising will view the process as beneficial, while students whose perceptions negatively correlate with their ideals of advising will doubt its efficacy" (280).

\footnotetext{
1 "involves mutual discussion and decision-making about which courses to take, when to take those courses, and underscores the salience of faculty-student mentoring" (Christian and Sprinkle, 2013:272)

2 "The faculty member is viewed as the authority and the student has little input into the advising process" (Christian and Sprinkle, 2013: 272).
} 
Similarly, Davis and Cooper (2001) examined students' perceptions of academic advising in relation to different advisors' styles, namely full-time faculty advisors, full-time professional advisors, and full-time residence advisors. Generally, the 198 surveyed respondents were satisfied with the academic advising they receive and perceive it as collaborative rather than prescriptive. However, professional advisors were rated a little higher than faculty advisors. The researchers justified such a little difference as faculty advisors usually have more workloads (teaching and research), and advising is one among other responsibilities they have to fulfill, whereas professional advisors' main responsibility is to advise.

In two qualitative studies, Alexander, Kukowski, and Dexter (2003 \& 2002) investigated the perceptions of 14 graduating Business seniors of the academic advising they receive at a university in the US. Using a 90minute interview with each of the randomly selected participants, the researchers, who analyzed their data thematically, identified 10 emerging themes. Out of those 10, Alexander, Kukowski, and Dexter (2003) presented their findings under three patterns, "(1) time spent with faculty advisors, (2) knowledge needed or possessed by advisors, and (3) comprehensive recommendations and suggestions on advising" (11). Although most of the participants seemed to be satisfied with the amount of time spent with their advisors, which ranged between less than a minute and 45 minutes, they recommended that their advisors set up " 15 to 30 minute blocks of advising time but permit students to sign up for the amount of time needed to reduce waiting time" (15). The participants also believed that their advisors would benefit from more training on advising though most of them possess enough knowledge about the university's major and liberal art course requirements. Most participants expressed their preferences to have (1) one-to-one advising rather than group advising sessions, and (2) one advisor throughout their studying years at the university rather than multiple advisors. Besides, the participants were not satisfied with the work of all the advisors; they reported that some advisors who disliked advising did "a poor job of it" (16). In their second study, Kukowski, Dexter, and Alexander (2002) reported their findings under two other patterns, "(1) advice received from faculty advisors, and (2) advice wanted or needed from faculty advisors" (41). The participants had different perceptions of the advising process. Some were satisfied with the advice they had received, a few others were disappointed with their academic advising. Generally, there was a good match between what advice the participants wanted and what advice they received.

From the aforementioned studies, it can be inferred that students' perceptions of advising are affected by the type of advertising they receive, the attitude as well as the knowledge of the advisor, and their expectations of academic advising. However, there seems not to be enough evidence that gender, major, and background could impact on students' perceptions toward advising. Thus, this research study tried to fill such a gap.

\subsection{Impact of Advising on Students' Success, Satisfaction, and Retention}

Not only were researchers interested in investigating students' perceptions of academic advising, several examined the impact of advising on students' success, satisfaction, and retention. Young-Jones, Burt, Dixon and Hawthorne (2013) surveyed 611 undergraduate students (from different majors, background, educational statuses and genders) about their expectations and experiences with academic advising. The researchers' aim was to investigate the relationship between academic advising and students' success or academic performance. The researchers found that "academic advising can vitally impact all facets of a student's academic experience, ranging from development of self-efficacy to practical applications of study skills" (15). They also found that the availability of the advisor to students and the number of times the student meets with his/her academic advisor lead to students' more perceived support by the advisor, which in turn contributes to their retention and success. This is also in line with Shelton (2003), who found that retention and success are directly related to the amount of support students feel in their university.

Hsu and Bailey (2011) also investigated the impact of Freshman Business students' views of academic advising and the difficulties faced in the college life on the students' retention in the university and in their major. They surveyed 913 students of both genders. The researchers found that students' satisfaction with advising impact on their retention. The faculty advisor's support in terms of answering advisees' questions and discussing their 4-year plan contributes to students' persistence in the university and their major (39). Besides, the researchers found that the participants who may not return had problems adapting to college life, which resulted in skipping classes more often and going home more frequently. Thus, Hsu and Bailey concluded that by improving the relationship between faculty advisors and students, students are likely to feel more supported and hence stay in their major and in the university.

Similarly, Soria (2012) investigated the relationship between advising and students' retention in the university. The researcher who surveyed a larger sample, 28,237 first-year students across a large public university in the US found that students' satisfaction with advising contributes to 'students' sense of 
belonging and retention" and that satisfaction with their advisors "is positively predictive of students' retention" (n.p.).

Sulton and Sanker (2011) also examined 15 pre-engineering students' satisfaction with the information provided to them by their academic advisors. Using mixed-methods, namely the survey and focus group, the researchers found that the participants were most satisfied with the "course-related information provided by advisors", least satisfied with "more immediate matters ... [such as] quality of faculty and internship opportunities" and moderately satisfied with information about "longer-term issues such as career opportunities" (75-76).

Therefore, it could be inferred that good advising contributes to students' satisfaction with the advising process, which in turn, impacts on their success and their retention.

\section{RESEARCH QUESTIONS}

One major question, with its three deconstructed questions, guided this research study:

What perceptions do our students have toward academic advising?

1. What are the attitudes of the students toward the academic advising they receive at the university?

2. To what extent are the students aware of the importance of academic advising as well as of the role of academic advisors on their university life?

3. Does gender, major, or status impact on the students' attitudes toward academic advising?

\section{METHODOLOGY AND METHODS}

As the problems addressed by social science researchers are usually complex, the combination of both quantitative and qualitative data collection methods "provides an expanded understanding of research problems" (Creswell, 2009: 203). That is why the researcher used a mixed methods design, which involves the use of quantitative and qualitative data collection methods.

\subsection{Data -Collection Methods}

The researcher employed a self-completion questionnaire, which consisted of 16 closed-ended questions (multiple choice and Likert scale) and 2 open-ended questions for richer data about students' attitudes. This questionnaire was piloted and revised before administering it to 185 participants, with a return rate of $100 \%$. The quantitative data were also complemented with 3 focus groups of 22 participants in total to get deeper insights into students' perceptions and attitudes. The researcher validated the transcriptions with the participants via e-mail.

\subsection{Participants}

185 participants were purposively sampled of different majors, genders and academic statuses at the university. More specifically, the sample consisted of 86 males and 99 females from the three schools at the university, namely business (98), engineering (73), and science information systems (14). The science information system was least represented due to the relatively small number of students enrolled in this school. The participants were also of different statuses: freshman (12), sophomore (23), junior (39), senior (85), and graduates (26).

\subsection{Data Analysis}

The data were analyzed both quantitatively and qualitatively. The researcher employed mostly descriptive analysis for the quantitative data using SPSS file (version 19). To determine whether male and female participants had different attitudes toward academic advising, the researcher used independent sample test (T-Test). In addition, one-way anova was used to determine whether the participants' major and status impact their attitudes toward advising. The qualitative data were thematically analyzed, and triangulation of methods is used to ensure validity of the findings.

\section{FINDINGS AND DISCUSSION}

\subsection{Attitudes of the Students}

Out of the 185 participants, about $83 \%$ indicated that they had received advising during their presence at our university, and $88 \%$ of the participants did so only in the pre-registration, advising week. However, these participants had different attitudes toward their academic advising. Only $38.4 \%$ rated their advising 
experience as helpful, and surprisingly, almost the same percentage $(37.8 \%)$ had a neutral response (neither good nor bad). However, $8.1 \%$ found it unhelpful, and $12.4 \%$ rated it as frustrating (see table 1 ).

Table 1. Attitudes toward Academic Advising

\begin{tabular}{|l|c|c|}
\hline & Frequency & Valid Percent \\
\hline Helpful & 71 & 38.4 \\
\hline Unhelpful & 15 & 8.1 \\
\hline Frustrating & 23 & 12.4 \\
\hline Neither Good or Bad & 70 & 37.8 \\
\hline Other & 6 & 3.2 \\
\hline Total & 185 & 100.0 \\
\hline
\end{tabular}

There was consistency in the participants' responses. Almost the same number of the participants $(38.5 \%)$ expressed their satisfaction with the advising they received, and surprisingly almost the same number, $37.8 \%$, were neutral to this process (see table 2 ).

Table 2. Evaluate Advising Experience

\begin{tabular}{|l|c|c|}
\hline & Frequency & Valid Percent \\
\hline Strongly Dissatisfied & 6 & 3.2 \\
\hline Dissatisfied & 38 & 20.5 \\
\hline Neutral & 70 & 37.8 \\
\hline Satisfied & 63 & 34.1 \\
\hline Strongly Satisfied & 8 & 4.3 \\
\hline Total & 185 & 100.0 \\
\hline
\end{tabular}

The qualitative data provided deeper insights about students' attitudes towards their academic advising, which complemented the limitations of the questionnaire and clarified some of the ambiguities in the participants' responses. Out of the 22 participants in the 3 focus groups, only 2 participants had positive attitudes towards their advising process. Both participants talked about their experiences with the same faculty advisor in the School of Business. One of them said that "my advisor is very helpful. Last fall, she plotted for me the path that I have to follow over the whole three years [sophomore, junior, and senior], and with this plan, I do not think I need to seek advising anymore". Then he added, "Although she was not enlisted as my academic advisor, I sought her advice when my advisor was not available and she did not mind it'. The other participant described her as a caring advisor who provided each student enough time for proper advising.

However, the others had very negative experiences with advising and advisors. Some of the terms they used to describe their advising experiences were "useless", "ineffective", and "misleading". For example, one participant said "I did advising twice in 4 years. I wish I did not... I had to change my major [from accounting to marketing] because of poor advising. I did not know that withdrawing from a course reduces my 3 chances of retaking that course, and my advisor did not tell me that. All what he told me was that I cannot fail a course three times. Because I withdrew from Accounting I [a required course] twice and got just a 60 [passing grade] on the third time, I could not take it for the fourth time to raise my grade at least to 70 [required grade for major courses]. Thus, I had to change my major, and my graduation was delayed one year". Then he added, "The other incident was with my marketing advisor who did not know that Marketing Research [a required course] can be taken with Statistics [another course] as a co-requisite. He insisted on being a pre-requisite, which I found out later to be untrue information. Since then, I decided not to seek advising from my academic advisor".

Another participant said, "My advisor insisted on my finishing all the 200 level courses before the 300 level, which delayed my graduation". A third participant, who was very furious, reported his experience with his advisor, which he faced at the end of his freshman year. His advisor insisted on his taking SAT II as a requirement to move to sophomore. Not being able to get the required score on the test, he was suspended from the university for one semester until he passed the test. Later on, he found out that as a Palestinian, he was exempted from taking this test. Thus, "I lost one semester due to poor advising".

The participants attributed these problems which they faced with their advisors to the following factors: (1) "advisors lack the required knowledge for advising", (2) "some advisors rush the advising process; they do not give enough time to check the student's course progress", (3) "neither advisors nor students take advising seriously", (4) "some advisors have inaccurate information about courses", and (5) "advisors lack experience with advising".

These findings were in line with other research in the literature. For example, Haag, Hubele, Garcia, and 
Mcbeath (2007) found that the complaints of their engineering participants about inadequate advising were partly due to their advisors' incorrect information about course requirements. Similarly, Young-Jones et al. (2013) stressed the importance of the availability of the advisor for his/her advisees on their feeling of being academically supported.

\subsection{Impact of Major, Gender, and Status on Students' Attitudes}

The impact of major, gender, and academic status on the participants' experiences with advising was almost negligible. The analysis of the t-test showed that there is an insignificant relationship between female and male participants with respect to their attitudes toward academic advising since the $p$-value is .861 , greater than .05 (at $5 \%$ level of significance) as indicated in table 3 below, which is in line with Gudep (2007). As to major and academic Status, the F-probability value in the Anova is .571 and .873 respectively, which are greater than .05 (at $5 \%$ level of significance) (see tables $4 \& 5$ ). In other words, there is no significant difference between business, engineering, and science information systems, and between sophomores, juniors, seniors and graduates with respect to their experiences with academic advising.

Table 3: Impact of Gender on Students' Attitudes

\begin{tabular}{|c|c|c|c|c|c|c|c|c|}
\hline & Gender & $\mathrm{N}$ & Mean & S.D & T & DF & F & P \\
\hline Attitudes & Male & 86 & -.0317295 & .97343498 & -.401 & 183 & .031 & .861 \\
\hline Attitudes & Female & 99 & .0275630 & 1.02665633 & -.403 & 181.581 & & \\
\hline
\end{tabular}

Table 4. Impact of Major on Participants' Attitudes toward Academic Advising

\begin{tabular}{|l|c|c|c|c|c|}
\hline & Sum of Squares & $\mathrm{df}$ & Mean Square & $\mathrm{F}$ & Sig. \\
\hline Between Groups & 2.946 & 4 & .737 & .732 & .571 \\
\hline Within Groups & 181.054 & 180 & 1.006 & & \\
\hline Total & 184.000 & 184 & & & \\
\hline
\end{tabular}

Table 5. Impact of Academic Status on Participants' Attitudes toward Academic Advising

\begin{tabular}{|l|c|c|c|c|c|}
\hline & Sum of Squares & $\mathrm{df}$ & Mean Square & $\mathrm{F}$ & Sig. \\
\hline Between Groups & 1.244 & 4 & .311 & .306 & .873 \\
\hline Within Groups & 182.756 & 180 & 1.015 & & \\
\hline Total & 184.000 & 184 & & & \\
\hline
\end{tabular}

\subsection{Students' Awareness of the Advising Process and Advisor's Role}

The participants seem to be aware of the importance of academic advising as $76.8 \%$ indicated that advising should be mandatory to each student (see table 6).

Table 6: Academic Advising Should be Obligatory

\begin{tabular}{|l|c|c|}
\hline & Frequency & Valid Percent \\
\hline Strongly Disagree & 13 & 7.0 \\
\hline Disagree & 13 & 7.0 \\
\hline Neutral & 17 & 9.2 \\
\hline Agree & 79 & 42.7 \\
\hline Strongly Agree & 63 & 34.1 \\
\hline Total & 185 & 100.0 \\
\hline
\end{tabular}

They also seem to be aware of the role an academic advisor should fulfill such as keeping track of each student's progress through his/her stay at the university (73.5\%) as indicated in table 7.

Table 7: Advisor Should Keep Track of Each Student

\begin{tabular}{|l|c|c|}
\hline & Frequency & Valid Percent \\
\hline Strongly Disagree & 6 & 3.2 \\
\hline Disagree & 15 & 8.1 \\
\hline Neutral & 28 & 15.1 \\
\hline Agree & 80 & 43.2 \\
\hline Strongly Agree & 56 & 30.3 \\
\hline Total & 185 & 100.0 \\
\hline
\end{tabular}


Most participants (84.9\%) believe that the advisor has to provide them with proper guidance and suggest alternative elective courses from which they can choose what suit them; that is, they require collaborative rather than descriptive advising (see table 8).

Table 8: Guide and Suggest Best Alternative

\begin{tabular}{|l|c|c|}
\hline & Frequency & Valid Percent \\
\hline Strongly Disagree & 7 & 3.8 \\
\hline Disagree & 4 & 2.2 \\
\hline Neutral & 17 & 9.2 \\
\hline Agree & 94 & 50.8 \\
\hline Strongly Agree & 63 & 34.1 \\
\hline Total & 185 & 100.0 \\
\hline
\end{tabular}

The qualitative data were consistent with the quantitative data. Despite their reported negative experiences with academic advising, the participants in the focus groups believe that advising should be "mandatory and useful especially for new students". One participant added "when this happens, we all will seek advising". The participants in the focus groups identified some qualities an advisor should have in order to ensure good advising, which also reflected their knowledge of the role of an academic advisor. Different participants named different qualities such as "devoting more time to their advisees", "advising only students of their majors", "being well informed and trained on advising", "planning the advisees' study paths", "briefing students about the university student handbook and warning them against problems they might face as in their GPAs", "provide proper orientation and guidance on our courses", "pay attention to students' needs and make stuff easier for them", "be available and respectful to students". These qualities match with what was presented in the literature about the duties of an academic advisor. For example, citing Varma and Hahn (2007) and Cogdell (1995), Sulton and Sankar (2011:73) listed two main functions of an academic advisor: "(a) to assist students in forming goals and devising plans for accomplishing those goals, and (b) to enable students to cope with any personal, intellectual, and institutional barriers that hinder the execution of that plan". Migden (1989:64) identified similar duties where the advisor should "... serve as referrals to [curricular and] other institutional services".

From what has been aforementioned, it could be noticed that most of the participants' experiences with academic advising do not match with their expectations of what academic advising is and what an academic advisor should do. This could explain a lot of the participants' frustration and negative attitudes toward academic advising (c.f. Kukowski, Dexter and Alexander, 2002), which led a lot of them to quit advising although they believe in its benefits when done properly.

\section{LIMITATIONS}

The findings are likely to be credible as the researcher ensured the participants' validation and used multimethod triangulation (Bryman, 2008). However, it would be unwise to claim that the different viewpoints among the students in the university were represented because the sample was not randomly selected and only the viewpoints of those participants who showed willingness to participate in both the survey and focus groups were included. This skepticism might also relate to the generalizabilty of the findings as the sample was selected from one university.

Despite its limited generalizabilty, this research should provide us with an idea about our students' perceptions of academic advising, the problems they face in their advising, and urge us to improve this process to make it better address our students' needs.

\section{CONCLUSION}

This study investigated the perceptions of university students of academic advising, their attitudes, their awareness of the process and of the role of the advisor, and the relationship between gender, major, or academic status on the participants' attitudes. Based on the collected data, a lot of the students seem to perceive the process poorly as they had negative experiences with their academic advising and advisors. In addition, their expectations of academic advising did not match with what they received from their advisors. This impacted their behavior and resulted in their not following the university policy of advising. However, this hinted at a gap in the advising process itself, namely the absence of follow up on the implementation of the procedure, and raised the following question: How were the participants able to register their courses without consulting with their academic advisor and most often without having their signature on the registration form? Unless this question is answered and the gap is filled, it is not likely that students will conform to the policy, and their perceptions of academic advising will be improved. 


\section{RECOMMENDATIONS}

To enhance students' attitudes and to meet their expectations of academic advising, the researcher recommends some changes as related to policy, university, advisors, and students.

1. Policy

a. The advising policy should be strictly enforced and monitored.

b. Students and faculty advisors should abide by the policy.

c. Each student should be advised by one faculty advisor of the same major as that of the student throughout his/her study years.

2. University

a. The university needs to update the system so that advisors can electronically keep track of students' records and courses, and students can automatically re-register in courses which they fail.

b. As the number of the students increase, the university should hire professional advisors or have an advising office, which is likely to reduce the stress on faculty advisors.

3. Advisors

a. Academic advisors should receive intensive training on advising.

b. Advisors should be available for their advisees and should provide them enough time for advising.

c. Academic advisors should have positive attitude toward advisees and advising, and they should be held accountable for their work.

4. Students

a. Students should not be able to register their courses before meeting with their advisors.

b. Students should take academic advising seriously and seek advising regularly.

These recommendations, which most of them are consistent with Knox (2003), are likely to increase our students' satisfaction with academic advising, to contribute to more positive advising experiences, and hence to improve students' perceptions of academic advising.

\section{ACKNOWLEDGEMENT}

The researcher would like to express gratitude to three students who helped in collecting the quantitative data, namely Ms. Nadine Sardouk, Ms. Dana Abou Zeid, and Ms. Lynn Kassem. Also special thanks go to all the student participants who were generous enough to open up and provide their time and sincere responses for this study.

\section{REFERENCE LIST}

Alexander, M. W., Kukowski, D., \& Dexter, L. (2003). Business Students' Perceptions of the Academic Advising Process. Proceedings of the Academy of Educational Leadership, 8 (1), Tunica, 11-16.

Astin, A.W. (1984). Student Involvement: A Developmental Theory for Higher Education. Journal of College Student Personnel, 25 (2), 97-307.

Bryman, A. (2008). Social Research Methods ( $3^{\text {rd }}$ ed.), Oxford University Press, New York.

Christian, T. Y. \& Sprinkle, J. E. (2013). College Student Perceptions and Ideals of Advising: An Exploratory Analysis. College Student Journal, 47 (2), 271-291.

Creswell, J. W. (2009). Research Design: Qualitative, Quantitative, and Mixed Methods Approaches (3 ${ }^{\text {rd }}$ ed.), Sage Publications, US.

Davis, J. S. \& Cooper, D. L. (2001). Assessing Advising Style: Student Perceptions of Academic Advisors. College Student Affairs Journal, 20 (2), 53-63.

Gudep, V. K. (2007). Issues and Challenges in Academic Advising: A Multivriate Study of Students' Attitudes towards Academic Advising in United Arab Emirates (UAE). Contemporary Management Research, 3 
(2), 151-172.

Haag, S., Hubele, N., Garcia, A., \& Mcbeath, K. (2007). Engineering Undergraduate Attrition and Contributing Factors. International Journal of Engineering Education, 23 (5), 49-61.

Hsu, M. \& Bailey, A. (2011). Retention in Business Education: Understanding Business Student Perceptions of Academic Advising and College Life. International Journal of Business and Social Science, 2 (21), 33-41.

Knox, D.E. (2003). Advisors and Mentors: Their Role in the Retention and Success of Chemical Engineering Students. Proceedings of the American Society for Engineering Education, Nashville, TN, 1-8.

Kukowski, D., Dexter, L. \& Alexander, M. W. (2002). Advice Received and Needed from Faculty Academic Advisors. Proceedings of the Academy of Educational Leadership, 7 (1), Nashville, 41-46.

Migden, J. (1989). The Professional Advisor. NACADA Journal, 9 (1), 63-68.

Nasser, R.N., Khoury, B., \& Abouchedid, K. (2008). University Students' Knowledge of Services and Programs in Relation to Satisfaction: A Case Study of a Private University in Lebanon. Quality Assurance in Education,16 (1), 80-97.

Shelton, E.N. (2003). Faculty Support and Student Retention. Journal of Nursing Education,42 (1), 68-76.

Soria, K. M. (2012). Advising Satisfaction: Implications for First-Year Students' Sense of Belonging and Student Retention. The Mentor: An Academic Advising Journal, available at: http://dus.psu.edu/mentor/2012/10/advising-satisfaction/ (accessed 27 May 2014).

Sutton, K. L. \& Sankar, C. (2011). Student Satisfaction with Information Provided by Academic Advisors. Journal of STEM Education, 12 (7\&8), 71-84.

Young-Jones, A.D., Burt, T. D., Dixon, S. \& Hawthorne, M. J. (2013). Academic Advising: Does it Really Impact Student Success? Quality Assurance in Education, 21(1), 7-19. 